\title{
La incidencia de los patronatos nacionales en la política educativa de las enseñanzas de sordos (1910-1978)
}

\author{
The influence of national boards on deaf \\ educational policy (1910-1978)
}

\section{Resumen}

El objetivo del trabajo es analizar la incidencia de los patronatos en las políticas educativas de las enseñanzas de sordos, desde el primer Patronato Nacional de Sordomudos, Ciegos y Anormales hasta el Real Patronato de Educación Especial (I910-I978). La metodología utilizada es la histórica, fundamentalmente el análisis de las fuentes documentales archivísticas y de normativa y la revisión de la obra bibliográfica existente, sobre los patronatos y las políticas educativas de los gobiernos y sus administraciones en las enseñanzas de personas sordas. El enfoque fundamental del trabajo se plantea desde la acción de los gobiernos y sus administraciones, es decir, desde sus políticas educativas. Las conclusiones se construyen sobre unos hechos y análisis que permiten entender la acción de los patronatos y su contribución en la evolución de las enseñanzas de sordos.

\section{Palabras clave}

Política educativa. patronatos nacionales. sordomudos. anormales. deficientes. minusválidos. discapacitados.

\begin{abstract}
The aim of this paper is to analyze the impact of national boards on educational policy related to the teaching of deaf individuals from the first Patronato Nacional de Sordomudos, Ciegos y Anormales (National Council for the Deaf, Blind and Abnormal) to the Real Patronato de Educación Especial (Royal Council of Special Education) (I9I0-I978). This study uses historical methodology, primarily the analysis of archival and documentary sources, legal documentation and existing bibliographic material on the national boards and educational policies related to the education of deaf or deaf-mute people carried out by governments and administrations. This paper focuses on the actions of governments and their administrations through their educational policies. The conclusions are drawn from facts and analyses which allows for the understanding of actions taken by the national boards and their contribution to the evolution of education for deaf people.
\end{abstract}

\section{Keywords}

Educational policy, national boards, deaf-mute people, disabled people, handicapped people.

\section{Alfredo Alcina Madueño <alfredo.alcina@madrid.org> \\ Inspector de Educación, Comunidad de Madrid}

\section{Luisa Navarro Juárez \\ <es@spreadthesign.com> \\ Coordinadora de Spread the Sign, España}

Para citar:

Alcina, A. y Navarro, L. (20I4): "La incidencia de los patronatos nacionales en la política educativa de las enseñanzas de sordos (I9IO-I978)", Revista Española de Discapacidad, 3 (I): I4I-I6O.

Doi: <http://dx.doi.org/IO. $5569 / 234$ O5 I04.03.01.08>

Fecha de recepción: 20-I I-20I4 Fecha de aceptación: 2I-05-20I5 


\section{Introducción. Precisiones, estado de la} investigación y temporalización histórica

La presencia y actividad de los patronatos nacionales como entidades en la historia de la educación especial en España se remonta a I9ro, lo que supone un periodo de más de roo años y haber estado presentes desde entonces en todos los regímenes políticos sucedidos hasta hoy. Desde el punto de vista histórico entre el Patronato Nacional de Sordomudos, Ciegos y Anormales de r9 Io y el actual Real Patronato sobre Discapacidad hay una larga línea que evoluciona con continuidades en muchos aspectos y sin éstas en muchos otros y es en este ámbito donde se ubica el objeto de este estudio: analizar la incidencia de los patronatos entre I9I0 y 1978 en la política educativa de las enseñanzas de sordos.

Procede hacer en este punto algunas apreciaciones semánticas de interés así como alguna precisión conceptual introductoria sobre las enseñanzas de sordos, pertinentes en tanto que este colectivo y su educación son también elementos protagonistas de este artículo.

Primera. Los términos que se utilizan en este trabajo, pongo por ejemplo el de anormales, deficientes o sordomudos se utilizan siempre con valor histórico, es decir, tal como se usaban en el periodo o periodos que se van a analizar y también la misma narración permite observar su evolución terminológica y conceptual. El caso del término sordomudo evoluciona hasta la expresión sordo en un número importante de idiomas por la incidencia de planteamientos educativos y sociales de naturaleza oralizadora que defienden que el sordo puede hablar y en consecuencia se pierde la parte de mudo. Sin embargo, esta evolución no tiene un correlato tan amplio en un importante número de lenguas de signos del mundo, cuyas configuraciones del signo del concepto sordo siguen haciendo referencia tanto a la sordez como a la mudez (Diccionario on line Spread the Sign), manteniéndose viva una idea que resurge en los tiempos de confrontación entre los enfoques o métodos educativos del siglo XIX y que significaba que el sordo "ni oía ni hablaba".

Segunda. La expresión enseñanzas de sordos utilizada tanto en el título del trabajo como en reiteradas ocasiones en el texto se recoge en plural con una fuerte intencionalidad connotativa, en tanto que a nuestro juicio la educación de las personas sordas en un contexto escolar desde sus inicios a finales del siglo XVIII hasta hoy, ha tenido enfoques educativos diferenciados que se orientaban por el uso (en mayor o menor grado) de los signos propios de las lenguas de signos o señas o bien se centraban en el uso de métodos y planteamientos que favoreciera el aprendizaje de la lengua oral nacional en su forma escrita y hablada, como eran el aprendizaje de la articulación, de la lectura labial o de la dactilología. Estos dos enfoques generales convivieron durante mucho tiempo, si bien no en armonía, sí con valores eclécticos compartidos en cuanto a procedimientos y técnicas y evolucionaron de forma específica cada uno dentro de sus modelos. En el último cuarto del siglo XIX en Europa y los Estados Unidos se produce una profunda confrontación de planteamientos que termina en que la educación de los sordos se plantee y ordene sin presencia de los signos y mucho menos de las lenguas de signos en los currículos educativos oficiales.

Consecuencia de la situación anterior, determinada línea de investigación considera que el enfoque oralizador hegemónico durante muchos años en la educación de los niños sordos presenta un fuerte componente ideológico, además de pedagógico, que se simboliza y define en un continuo de consideraciones, pensamientos y creencias de las cabezas y voces más significadas del Congreso Internacional de Profesores de Milán de I 880 y sus sucesores (Lane, I989:376-4I4).

Estos modelos educativos oralizadores con objetivos muy potentes como el de integrar al sordo en la sociedad y de resultados mediocres y muy desiguales que las administraciones educativas hacen suyo y lo imponen en sus políticas, empezarán a cambiar paulatinamente 
en la década de los años I970 al modificarse la concepción de la educación de los sordos y de sus derechos lingüísticos y civiles. En países como Suecia o EE.UU surgirán nuevas propuestas y el modelo educativo para los sordos se hará, también lentamente, plural y diverso dentro de la heterogeneidad propia de las personas sordas. Y en un mundo educativo cada día más globalizado surgirán universales educativos a escala internacional como la integración escolar del niño o joven sordo apoyada en una tecnología médica (implantes cocleares) que está provocando una revolución en la forma de abordar la sordera y también el reconocimiento de las lenguas de signos como idiomas de cultura y educación y que darán lugar a programas y planteamientos bilingües (lengua de signos y lengua oral). Hoy, los sistemas educativos más modernos, con fuertes valores de calidad y equidad, buscan respuestas que principalmente beneficien al alumnado sordo y a ello han contribuido, estamos convencidos, los patronatos más modernos en España o figuras similares en otros países.

Hechas estas consideraciones que van a favorecer la comprensión de la exposición se vuelve a la línea inicial y se plantean tres periodos con cierta unidad cada uno en el lapso I9IO-I978 para el análisis de la incidencia de los patronatos nacionales en las enseñanzas de sordos en España. El primero es el de la institucionalización I910-I936; muy diverso en cuanto a modelos y que recorre la Restauración y la República. Un segundo periodo, muy parco en cuanto a estas corporaciones y de funciones premodernas se circunscriben al régimen de Franco y un tercero, muy intenso en el tiempo, relativo al posfranquismo y la Transición política (I975-I978). Los patronatos reales que se crean a partir de la Constitución de I978: el Real Patronato Nacional de Atención a Deficientes, el de Prevención y Atención a Personas con Minusvalías y el actual Real Patronato sobre la Discapacidad, serán objeto de otro trabajo.

La bibliografía o trabajos de investigación específicos tanto sobre los patronatos nacionales de la educación especial como de las políticas sobre las enseñanzas de sordos en el marco temporal y del objeto del artículo se centran fundamentalmente en: Molina, I900,1903; Pereira, I904; López Núñez, I908; Orellana, I9I4; Navarro, I917,I926; Granell, I932; García Maroto, I935; Polaino-Lorente, I983; García Pastor y García Jiménez, I987; Herráiz, I992, I995, 2000; Cabada, I992; Molina y Gómez, I992; Del Cura, 20I 2. También y dadas las fuentes utilizadas en este trabajo hay que citar a la administración que a lo largo del periodo estudiado se ha expresado y manifestado a través de un conjunto de disposiciones, reglamentos y decretos y que han supuesto su contribución a la solución, ordenación y regulación de los distintos aspectos que se tratan en este artículo. Estas disposiciones se presentan de forma sucinta en notas a pie de página y en extenso en la sección de normativa de la bibliografía.

Las características estructurales más regulares a lo largo del tiempo de los patronatos que tenían y tienen como objeto de su actividad a los distintos colectivos de personas con deficiencias, minusvalías o discapacidades son:

A) Siempre han sido y siguen siendo instituciones oficiales, en consecuencia públicas y financiadas básicamente por los presupuestos del Estado. B) Su dependencia administrativa siempre se ha realizado en el ámbito ministerial, no siempre el mismo, y discurre desde los de instrucción pública o educación hasta los de naturaleza social-sanitaria. C) Estas instituciones no tuvieron personalidad jurídica salvo excepciones (Patronato Nacional de Sordomudos y Ciegos concedida por el Real Decreto de 3 I de diciembre de I926). D) Su objetivo siempre ha sido y es dar una respuesta global, comprensiva y coordinada a los colectivos a los que se dirigía en los ámbitos más significativos para éstos y que a lo largo del tiempo han sido el educativo, el sanitario y el social.

E) Los patronatos nacionales han sido siempre instrumentos en las políticas educativas, sociales y sanitarias de los gobiernos para los colectivos indicados, si bien, desde el punto de vista histórico no siempre desarrollaron las mismas competencias ni fue la misma la naturaleza de las acciones, lo 
que se correlaciona directamente con la evolución del Estado español en los campos manifestados. Así, durante muchos años los patronatos tuvieron la competencia de la inspección superior sobre los centros educativos de sordomudos, ciegos y anormales y sobre los programas o currículos que impartían éstos o también la selección y clasificación del alumnado de educación especial, entre otras muchas competencias, las cuales han evolucionado y se han transformado consecuencia de la misma evolución del Estado. Estas instituciones, expresado de manera simplificadora, han pasado de la realización específica de muchas de las acciones anteriores a su promoción, coordinación y difusión.

Los patronatos como elementos institucionales del Estado son una realidad adaptativa, en muchos casos paralela a la misma evolución que la sociedad tiene sobre los colectivos y personas objeto del artículo y que tiene un buen indicador en el cambio semántico de sus denominaciones: de anormales a deficientes y minusválidos y de éstos a discapacitados.

2. Primera etapa: la institucionalización de los patronatos (1910-1936)

La regeneración educativa en los primeros años del siglo XX se aborda gracias a la acción de los programas conservador y liberal, representados por los ministros de Instrucción Pública García Alix, que para Carr (2000:457) representa "el primer ensayo de regeneración desde la derecha...”, y por el liberal Álvaro de Figueroa.

\subsection{Las enseñanzas de sordomudos al inicio del siglo $\mathrm{XX}$}

El subsistema escolar de las enseñanzas de sordomudos es funcionalmente independiente y estanco en el conjunto del sistema educativo, siendo indicadores de esta situación que sus maestros no forman parte del Escalafón General o que la Inspección provincial de
Educación en su función de formación del magisterio no dedica ni una sola conferencia a estas enseñanzas en los principios del siglo XX (Ministerio de Instrucción Pública, I908:34-4I).

El secretario del Colegio Nacional de Sordomudos y de Ciegos de Madrid, Pedro Molina (I 900:3-5) considera que solo el 4, I $4 \%$ de los sordomudos y el I, $48 \%$ de los ciegos están escolarizados en los años finales del XIX y primeros del XX entre I4 establecimientos, unos son provinciales y locales sostenidos por diputaciones y ayuntamientos, un solo colegio estatal financiado por la Administración Central del Estado (Colegio Nacional de Sordomudos y de Ciegos) y los demás son privados. La población sordomuda en España en edad escolar a principios de siglo se estima entre las $9000 \mathrm{y}$ I I000 personas (Molina,I903:I0).

El aparato administrativo de estas enseñanzas está muy centralizado y es mínimo, una Sección de la Dirección General de Primera Enseñanza del Ministerio de Instrucción Pública y Bellas Artes que se completa con la estructura de la Comisaría Regia y su secretaría para el Colegio de Sordomudos y de Ciegos de Madrid.

\subsection{Las enseñanzas de sordomudos se modernizan}

Las enseñanzas de sordomudos también forman parte de las enseñanzas que se modernizan en el proceso de regeneración del sistema educativo iniciado a principios del siglo XX, y producto de esta iniciativa se asientan nominalmente los principios teóricos de estas enseñanzas que regirán básicamente hasta el último tercio del siglo XX.

El proceso de modernización se hace por dos vías, la primera, por la administración educativa del ministro Álvaro de Figueroa tomando como objeto el Colegio Nacional de Sordomudos y a través de su Reglamento de octubre de $1902^{\mathrm{I}}$, en

I. Exposición de Motivos del Real Decreto de I7 de octubre de I902 que aprueba el Reglamento del Colegio Nacional de Sordomudos y de Ciegos. 
el que se insertan un conjunto de principios cuya incidencia real en esos años es nula o mínima y que se pueden concretar en:

a. Un proceso de normalización de las etapas impartidas en el Colegio con respecto al régimen escolar general y de adaptación de sus currículos a los ordinarios.

b. La necesidad de establecer un nivel de educación especial inserto en el sistema educativo y armonizado con el ordinario y que permita el desarrollo de una red pública y privada, unificada, especializada y diferenciada de la ordinaria, con una organización de los centros escolares basada en grupos homogéneos y la clasificación rigurosa y científica del alumnado y aprendizaje del lenguaje oral, siguiendo los planteamientos del Congreso de Profesores de Milán de 1880 y una formación moderna del profesorado especial de sordomudos.

c. La necesidad de la escolarización del alumnado sordomudo por encima de lo existente.

La segunda vía de modernización o de reforma de esas enseñanzas se produce por la posición de los profesionales del sector a través de la Asamblea de Profesores de Sordomudos y de Ciegos de I906, que supone la crítica más sistemática, ordenada y coherente de los distintos sectores profesionales de las enseñanzas de sordomudos y de ciegos a las políticas educativas de la Ley de Instrucción Pública de I 8 57. Además, pretenden que sus conclusiones vertebren la acción y las políticas de la administración educativa en estas enseñanzas y entre las más significativas destacamos la confección de estadísticas, la formación del profesorado específico de sordomudos y de ciegos, la oralización del alumnado, la incorporación de talleres profesionales, las políticas de prevención de la sordera y ceguera o la financiación de la red escolar (Ministerio de Instrucción Pública, I908:46I-462).

Estas vías o medios no son distintos a los que se utilizan en otros países avanzados y las ideas, ideologías e iniciativas que sustentan son el magma en el que los miembros más progresistas de la administración educativa y los sectores profesionales más avanzados se mueven. En I9Io se crea el Patronato Nacional de Sordomudos, Ciegos y Anormales, producto o creación del regeneracionismo y de los postulados teóricos sobre estas enseñanzas. No hay salto en el vacío, los métodos experimentales y la extensión de las disciplinas educativas de la educación especial se han empezado a materializar en Francia, Alemania, Inglaterra o Bélgica, pronto algunos de estos países tendrán comisiones especiales que estudiaran la enseñanza especial y en no muchos años dictaran leyes sobre la nueva etapa (Francia e Inglaterra, I909 y I9I3). Aquí se hace de otra forma, se obvia la discusión parlamentaria y la acción puramente legislativa y se crea una Educación Especial por decreto.

Aún así, la administración educativa actúa bajo criterios de racionalidad y en I9 Io se intentan conseguir los recursos económicos necesarios para la implantación de la Educación Especial mediante un empréstito de I 500 millones de pesetas para la "Construcción de Edificios para Escuelas públicas, Colegios, Escuelasmodelos de niños sordo-mudos, ciegos y demás anormales" ${ }^{2}$. No nos consta que consiga la financiación ni que se construyan las escuelas. Ante esta imposibilidad la medida financiera que se toma por el gobierno es incrementar las partidas económicas de los Presupuestos del Estado para el Colegio Nacional de Sordomudos y de Ciegos $^{3}$. Por este procedimiento, el nuevo Patronato Nacional de Sordomudos, Ciegos y Anormales, su sede, su personal y sus gastos administrativos son atendidos desde los presupuestos del Colegio de Sordomudos y de Ciegos y también el desarrollo de las enseñanzas

2. Real Decreto de I de octubre de I9 Io del Ministro de Hacienda, Gaceta de Madrid de 7 de octubre de I9Io. También hay una referencia de dicho Proyecto de Ley en el Diario de Sesiones de 6 de octubre de I9Io. Congreso de los Diputados. Diario de Sesiones. 29. Serie Histórica (I8I2-I936), I910I9I 5 .

3. Proyecto de Ley de los Presupuestos Generales del Estado para el año económico de I9I I, de 2 de julio de I9Io. Diario de Sesiones de 15 de octubre de I9ro. Congreso de los Diputados. Diario de Sesiones. 29. Serie Histórica (I 8I 2-I936), I9IO-I9I 5 . 
de anormales. Esta situación provocó siempre un fuerte conflicto entre las secciones o colectivos profesionales de los distintos patronatos.

2.3. Los patronatos en el periodo 1910-1936: su evolución y aportaciones a las políticas educativas de ámbito didáctico, de red escolar y de formación del profesorado especialista de sordomudos

En cuanto al diseño y creación del Patronato son gobiernos del Partido Liberal los que lo establecen en r9 Io a petición del ministro de Instrucción Pública, Barroso, del Gabinete José Canalejas ${ }^{4}$. Según el decreto de creación el Patronato inicia "la política intervencionista, vigente hoy en todas las legislaciones europeas" y se plantea bajo "una idea de unidad en la acción, y de esfuerzos y que deviniese en un prestigioso cuerpo consultivo que fuese constante asesor del Ministerio en todo lo referente a estos asuntos”.

El Patronato presenta un conjunto de atribuciones de naturaleza principalmente consultivas y también ejecutivas que abarcan toda la política educativa que la administración educativa quiere diseñar y aplicar ${ }^{5}$, pero pronto el Patronato va a ser el marco de una lucha política y gremial, que no es solo propia de España y que se lleva a cabo entre sectores de pedagogos, médicos y psicólogos, tanto para que sus visiones y argumentos determinen la organización del nuevo sector como para establecer su presencia en las direcciones de los

4. Real Decreto de 22 de enero de I9ro por el que se establece un Patronato Nacional de sordomudos, ciegos y anormales.

5. El Patronato Nacional de Sordomudos, Ciegos y Anormales es una corporación principalmente consultiva encargada de informar al Ministerio en todo lo referente a la protección higiénica, social y pedagógica de los colectivos a los que agrupa, estando el Ministerio obligado a realizar la consulta en determinados ámbitos (organización y reforma de planes y reglamentos de enseñanza. Exámenes, grados y cátedras. Subvenciones a instituciones protectoras o recursos de alzada). El Patronato tiene funciones ejecutivas en el ámbito educativo, en el del cuidado y prevención y en el de la tutela social: hacer la estadística de sordomudos, ciegos y anormales. La profilaxis y la higiene. La tutela social. La vulgarización de los conocimientos. La alta inspección de los establecimientos de enseñanza y de las instituciones protectoras $\left(\operatorname{art.~} 5^{\circ}\right)$. nuevos organismos y del sistema formativo que tendrá que crearse ${ }^{6}$. Además, los patronatos se constituyen en moneda de cambio entre los políticos conservadores y liberales.

Las incidencias en las enseñanzas de sordomudos del primer Patronato son de difícil cuantificación directa, y no porque no hubiera representantes cualificados en la sección de Sordomudos, ya que estaban el comisario regio del Colegio Nacional de Sordomudos y de Ciegos Bejarano y su director Granell. Tampoco en la sección de Anormales, para determinados miembros del sector médico, la actividad parece mejor:

"Este Patronato estuvo 4 años deliberando y discutiendo, sin llevar nada a cabo. Cuando llegó el Sr. Bergamín al ministerio hace dos años, y vio aquella obra estéril de 4 años, reformó el Patronato nombrando presidente al Sr. Barroso" (González, I9 I7:I2).

Del Pozo ( I980) considera que sí hubo avances o al menos la actividad del Patronato influyó en la normativa de I9I 3 que estableció secciones de anormales en las escuelas graduadas o la presencia de la inspección médica en la clasificación de los niños anormales. Parece razonable pensar que al menos sí hubo una acción difusa en el sector.

En I9I4 se reforma el Patronato Nacional de Sordomudos, Ciegos y Anormales a propuesta del ministro de Instrucción Pública, el conservador Francisco Bergamín, pasando a denominarse Patronato Nacional de Anormales 7 . Se crea para resolver el problema de la educación pública de los niños anormales y según la exposición del decreto porque “(...) la presencia de los niños anormales de distintas variedades entorpece la enseñanza de las clases

6. El Dr. Lafora dice sobre el Colegio Nacional de Sordomudos: "A costa de los niños anormales, sordomudos y ciegos, se está nutriendo una banda de aves de rapiña que ha caído sobre el Colegio...”. En Molina y Gómez, I992: 24I.

7. Real Decreto de 24 de abril de I9I4, reformando el

Patronato Nacional de Sordomudos, Ciegos y Anormales, disponiendo que en lo sucesivo se denomine Patronato Nacional de Anormales. 
ordinarias y perjudica así la educación de los niños normales" y también "porque las distintas variedades de niños anormales necesitan una pedagogía especial...”. Para el Ministerio de Instrucción Pública lo urgente es la creación de escuelas para los anormales mentales ${ }^{8}$.

En la nueva ordenación de la educación especial, el remodelado Patronato se concibe como un instrumento de ejecución e intervención centralizada de la administración con unas funciones definidas y novedosas que se dirigen a todo el alumnado anormal constituido por sordomudos, ciegos y anormales y que se centran en el reconocimiento de la anormalidad infantil y su tratamiento, además de la formación de los profesionales. También, el Patronato desarrolla funciones directivas tanto sobre los centros educativos especiales como en los nuevos organismos que se constituyen en ese periodo. El decreto contempla una organización territorial estable.

Para hacer posible las funciones estatutarias se crea un Instituto Central con un Laboratorio médico-psicológico que lleva a cabo el reconocimiento de la anormalidad y la organización de cursos de formación de maestros y médicos inspectores de esta especialidad. Se crea el cargo de secretario general del Patronato que también es el director de toda la obra y de los establecimientos para anormales, incluido el Colegio Nacional de Sordomudos y Ciegos. El Patronato está presidido por el anterior ministro de Instrucción Pública Barroso?.

Este Patronato tiene una incidencia importante tanto en las enseñanzas y organización del Colegio de Sordomudos de Madrid como en el sistema general de estas enseñanzas. En el caso del Colegio de Madrid el efecto se concreta en

8. En esa misma línea de pensamiento se encuentra el maestro de primera enseñanza Francisco Pereira, vocal de la Sección 3 del Patronato Nacional de Sordomudos, Ciegos y Anormales, promotor en España de las escuelas de anormales.

9. El diputado Vincenti señala que el nuevo patronato es presidido por el ministro que presentó o creó el anterior. Diario de Sesiones de I I de diciembre de I9I4 de Enmiendas al Proyecto de de Presupuesto del MIPyBA de I9I 5 . Esto no será la última vez en producirse. que la dirección y gobierno del Colegio pasa a la Comisión ejecutiva y al secretario general del Patronato $^{\text {10 }}$ y desaparece la Comisaria regia. Una vez que el Colegio está bajo la dirección del Patronato se inicia la transformación del centro en una organización de enseñanza graduada y se profundiza en el enfoque metodológico oralista, que como se indicó más arriba, son dos aspectos de la reforma de principios de siglo de las enseñanzas de sordomudos.

La graduación de las enseñanzas requiere la previa clasificación del profesorado, transformando a los profesores auxiliares (Reglamentos de I902) en profesores de sección o grados en que se dividen las enseñanzas (Reglamento del Colegio de I9I 5, Disposición Transitoria $\mathrm{I}^{\mathrm{a}}$ ). Todavía en I9I9, cuatro años después, la autoridad competente requiere a la dirección del Colegio que se lleve a cabo tal modelo organizativo ${ }^{\text {II }}$.

En cuanto a la oralización del alumnado sordomudo se concreta o tiene un buen indicador en las pruebas para acceder al profesorado especial de sordomudos, los aspirantes tienen que practicar ante dos alumnos de dicha sección procedimientos de lectura oral y labial, con exclusión de toda mímica artificiosa. En la educación del sordomudo se defiende la adquisición del lenguaje de la palabra, formulación mantenida por el profesorado más prestigioso, entre otros por María Luisa Navarro (I9I7:287), jefa de Estudios del Colegio de Madrid.

Procede hacer dos últimas consideraciones de este Patronato de naturaleza e intención más genérica, si bien con afectación en el Colegio Nacional de Sordomudos y de Ciegos de Madrid, la primera es la creación de colegios de anormales mentales, ubicando uno de éstos en las instalaciones del Colegio, si bien,

Io. Reales Decretos de 24 de abril de I9I4 y 2 de marzo de I9I 5 .

I I. Oficio de la Dirección del Instituto Nacional de Sordomudos, Ciegos y Anormales, Castellana, 69, de 3 de junio de I9I9, destinado a una serie de profesores de sección. Documento sin numerar. Carpeta ${ }^{\circ} 5$ María Luisa Navarro. Fundación Ortega y Gasset. CSIC, Madrid. 
previamente el presidente del Patronato pidió la opinión del Claustro que lamentablemente desconocemos $^{12}$. Los alumnos sordomudos del Colegio se amotinan ante la presencia de aquellos, situación que fue sofocada por la Guardia Civil según Yuste de Santos (2013:45). La segunda incidencia es la renovación del sistema formativo del profesorado especialista de sordomudos y de ciegos:

“[...] a partir de I9I5 a I9I6 se suprimirá la asignatura de Métodos y Procedimientos para la enseñanza de Sordomudos y de Ciegos, creada por Real orden de 25 de marzo de I 857 , pasando estas enseñanzas á formar parte de las que incumben al Instituto Central de Anormales para la formación de Maestros de esta especialidad" ${ }^{13}$.

Y se pone en funcionamiento el Seminario de Maestros del Instituto Central de Anormales que tiene como estructura física el Colegio de Sordomudos y de Ciegos (Art. $2^{\circ}$ del Reglamento del Colegio de Sordomudos de I9I 5).

El Patronato Nacional de Anormales realiza sus funciones durante dos años escasos, ya que el ministro de Instrucción Pública Burell en marzo de I9I 6 deshace lo hecho y la estructura vuelve a la conocida organización del Patronato de Sordomudos, Ciegos y Anormales de I9IO ${ }^{\text {I4 }}$. En la exposición del real decreto de restablecimiento se justifica en estos términos:

“[...] para que cada uno permanezca y se mueva en sus respectivas esferas sin confusiones que esterilicen o entorpezcan los esfuerzos de todos... Conviene que la parte docente en el Instituto Nacional de Anormales y especial de Sordomudos y Ciegos proceda con independencia de todo otro fin, así como que la Administración mantenga su derecho de intervención".

I2. Documento sin numerar. Carpeta ${ }^{\circ} 5$ María Luisa Navarro. Fundación Ortega y Gasset. CSIC, Madrid.

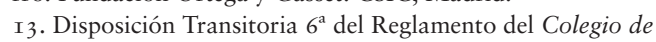
Sordomudos de I9I 5.

I4. Real Decreto de Io de marzo de I9I6 restableciendo la organización del Patronato de Sordomudos, Ciegos y Anormales.
Es una argumentación críptica y cuyo verdadero significado tienen que ver con el deseo del ministro de realzar la dirección pedagógica frente a la estructura profesional médica que para él ha copado el Patronato Nacional de Anormales. El presidente de la nueva forma es el conservador Bergamín, que fue el patrocinador del anterior Patronato de Anormales como ministro.

La estructura del Patronato Nacional de Sordomudos, Ciegos y Anormales de г9r6 mantiene las tres secciones de su creación entre marzo y agosto, pero en este mes mediante dos reales decretos de la misma fecha pero separados por cinco días en su publicación, el ministro cambia la estructura a dos secciones: Sordomudos y Ciegos por un lado y Anormales por otro y los inserta en un denominado y confuso Patronato del Instituto Nacional de Anormales y Especial de Sordomudos y Ciegos, con ro consejeros por cada una de las secciones. El segundo real decreto aprueba un nuevo reglamento para el Colegio Nacional de Sordomudos, Ciegos y Anormales en su instituto Nacional, reglamento para una nueva y creativa denominación que presenta entre otras novedades para el Colegio, que la dirección pedagógica y la alta inspección se adscriban al presidente del Patronato y el gobierno del establecimiento al director administrativo. El ministro se asegura el control del Colegio de Sordomudos y de Ciegos, sin bien la incidencia de la nueva fórmula en las enseñanzas de sordomudos es de difícil valoración.

Consecuentemente con la nueva denominación tanto del Colegio como del Patronato, el ministro Burell sí consolida las enseñanzas de anormales creando orgánicamente una Sección de Anormales bajo un director técnico y formada por dos escuelas y un seminario, con una regulación y organización notablemente moderna. Sección que “(...) tan pronto los alumnos anormales pasen a otro edificio (están en las instalaciones de Castellana del Colegio de Sordomudos y de Ciegos), se convertirá en Patronato independiente". En diciembre de I9I 6, estando todavía los alumnos anormales en las instalaciones citadas, el ministro Burell provoca la transformación del Patronato de dos 
secciones en dos patronatos independientes, el de Anormales y el de Sordomudos y Ciegos ${ }^{15}$. El motivo no está justificado ni es claro ${ }^{16}$.

Tras el cese en abril de I9I7 del conde de Romanones, jefe del Gabinete al que pertenece Burell como ministro de Instrucción Pública, el nuevo ministro de Instrucción Pública, el conservador Andrade Navarrete (abril-noviembre de I9I7) perteneciente al Gabinete Dato, decide que es más oportuno que el número de Patronatos que gestionan la educación especial sean 3 y no 2 , de tal manera que sordomudos y ciegos tuvieran cada uno el suyo independientemente. El ministro ha tardado 3 meses en hacer su reforma de la dirección institucional de la Educación Especial ${ }^{17}$ y se justifica en el decreto en que "(...) la intensidad de la vida de las instituciones sociales, está en razón directa de su especialización. A este fin parece prudente la formación de tres patronatos". Para Andrade el esfuerzo realizado por la administración y sus ministros de Instrucción Pública en estos últimos 7 años es importante y pueden darse por bien empleados.

Las atribuciones de cada uno de los Patronatos siguen siendo las conocidas pero aportan una idea original beneficiosa para el sistema educativo: “(...) interesa relacionar a los Patronatos con el Consejo de Instrucción Pública, mediante el ingreso de los Presidentes en el mencionado Cuerpo consultivo en calidad de vocales natos" (exposición del decreto). Además, en el mismo decreto se establece el compromiso de definir el significado real de la competencia de "la alta inspección", hecho que no tenemos constancia que se produjera.

I 5. Real Decreto de 22 de diciembre de I9I 6 por el que se establece que las dos secciones del Patronato se constituyan en dos patronatos independientes.

I6. En la prensa de aquellos días, el Dr. Lafora, enemigo acérrimo del ministro hace alguna consideración sobre la visita de éste al Colegio Nacional de Sordomudos y de Ciegos: “(...) encuentra algunas deficiencias en el primero y decide de un plumazo destituir al Patronato y nombra a un amigo suyo. Debemos hacer constar que la mayor parte de las deficiencias encontradas por el Sr. Borrell eran defectos de construcción del edificio y de la presencia de la Escuela de Ingenieros Industriales" (González, I9I7: I2).

I7. Real Decreto de 24 de agosto de I9I7 por el que se crean tres patronatos independientes.
El periodo de actuación de estos tres Patronatos se extiende hasta 1924, y en cuanto a las aportaciones del de Sordomudos afirmamos que tiene incidencia en la oralización del alumnado, al promoverse y crearse una oferta específica de ortoepía (pronunciación correcta) en el Colegio de Sordomudos de Madrid por medio de una Sección de niños disártricos cuyo profesor fue Jacobo Orellana ${ }^{18}$.

No parece que tuviera el indicado Patronato Nacional repercusión en la creación de plazas escolares para los sordomudos ya que no sufren variación sensible a nivel general, a pesar de un crédito de $250.5 \mathrm{I} 7$ pesetas para las obras del nuevo edificio del Colegio de Sordomudos de Santiago de Compostela en su nueva sede. Tampoco estas enseñanzas se benefician de los acuerdos en I922 y 23, entre el Ayuntamiento de Madrid, Ministerio de Instrucción Pública y la Junta de Instrucción Primaria de Madrid, ya que no se llegó a realizar el grupo de sordomudos y de anormales de los seis grupos previstos (Del Pozo, I999:229 y 246).

La Dictadura de Primo de Rivera, a través de su Directorio Militar en I924, reorganiza los patronatos que funcionan desde I9I7 y los trasforma en dos, dando lugar al Patronato Nacional de Sordomudos y de Ciegos y al Patronato Nacional de Anormales. Se justifica porque los Patronatos no funcionan con regularidad. El nuevo Patronato ${ }^{19}$ ejerce un mayor control en la acción tutelar administrativa de los centros privados y en la inspección sobre los claustros y profesionales de los Colegios Nacionales de Sordomudos y de Ciegos.

Además, se determina que la responsabilidad máxima de los Colegios Nacionales recaiga en un comisario regio con el fin de conseguir la eficacia y unidad necesarias. Esta figura desaparecida de la escena de estas enseñanzas en

I 8. Hoja de Servicios de Jacobo Orellana. Archivo de Clases Pasivas. Ministerio de Hacienda. El profesor tuvo una gratificación de 2000 pesetas/año según los Presupuestos de I922, Real orden de 24 de agosto de 1922.

I9. Real Decreto de I3 de septiembre de I924, reorganizando el Patronato Nacional de Sordomudos y de Ciegos. 
I9I 5, al restablecerse provoca serios conflictos competenciales con el Patronato, cuya dirección de los Colegios Nacionales se ejerce a través de un administrador. En I930, en una situación máxima de centralización de las competencias, se ordena que la Comisaría regia concentre todas las atribuciones de dirección e inspección sobre estas enseñanzas (Real Decreto de 5 de abril de I930).

El Patronato Nacional de Sordomudos y de Ciegos, como los anteriores, profundiza en la acción oralizadora extendiendo al sistema escolar general las enseñanzas de ortoepía (pronunciación correcta), de tal forma que un profesor del Colegio de Sordomudos asista a otros colegios de Madrid en los que haya niños disártricos (Orden de I I de septiembre de I924). También, las enseñanzas de disártricos se hacen obligatorias en el sistema formativo del profesorado especial de sordomudo a partir de I924.

La aportación más sustantiva de la Dictadura a las enseñanzas de sordomudos es adscribir en I925 la formación especializada de sordomudos a la Escuela de Estudios Superiores del Magisterio conjuntamente con el Colegio Nacional de Sordomudos y de Ciegos, articulándose un nuevo Curso Normal de Profesores Especiales de Sordomudos y de Ciegos de dos años académicos de duración, uno más que en el anterior modelo y con contenidos modernos. Este modelo de formación desaparece en I930, en nuestra opinión por una decisión política que se debe entender dentro del proceso de máxima concentración de poderes del nuevo comisario regio (López Núñez), del cual dependerá la formación del profesorado especializado.

La política educativa relativa a las enseñanzas de sordomudos durante los años I923-I93I, periodo relativo a la Dictadura de Primo de Rivera y del gobierno del general Berenguer (I930-3I), presenta una fuerte unidad con la del periodo anterior (I9IO-I923), si bien con la característica citada: su fuerte centralización en la dirección de las enseñanzas de educación especial (sordomudos, ciegos y anormales).
El último tramo de este periodo I9Io-I936 es el republicano, cuya política educativa se lleva a cabo por los ministros de Instrucción Pública Marcelino Domingo, Fernando de los Ríos y Domingo Barnés entre I93 I y I933. La política relativa a las enseñanzas de sordomudos tiende a conseguir modernizar las enseñanzas de sordomudos, extender su red escolar y proporcionar una organización moderna al Colegio Nacional de Sordomudos, el único de la Administración Central del Estado en su especialidad. Si bien, no son objetivos nuevos, ya que son los mismos que los formulados en las distintas fases de la Restauración, se conciben de forma más coherente e integrada en el sistema escolar, lo que no quita que determinadas decisiones políticas provoquen el cierre del Colegio Nacional de Sordomudos y de Ciegos de Madrid en I932.

En estos años el Patronato de Sordomudos y de Ciegos no ejerce más que funciones consultivas y además se le adscribe un delegado del gobierno, el comisario de la República en los Colegios Nacionales de Sordomudos y de Ciegos, Sidonio Pintado (El Magisterio Español de 9 de julio de I93I). En septiembre de I933 se promueve por Lerroux el único decreto que establece la organización de los Colegios de Sordomudos y de Ciegos de Madrid, y además deroga todos los reales decretos, reales órdenes y reglamentos que se dictaron por los gobiernos de Alfonso XIII para los Colegios Nacionales de Sordomudos y Ciegos, incluso las competencias del propio Patronato Nacional de Sordomudos y de Ciegos de I924 sobre el Colegio.

En febrero de 1934 se crea el Patronato Central ${ }^{20}$ por el ministro de Instrucción Pública Pareja Yébenes que sustituye al anterior Patronato. Como justificación y en la exposición de motivos del decreto se hace alusión a "la organización y vida mezquina que llevan los centros de sordomudos, ciegos y maternales". Sus funciones son las ya conocidas pero definidas con claridad en consonancia con el mandato que tiene: averiguar las causas del estado de

20. Decreto de I 6 de febrero de I934, por el que se crea el Patronato Central. 
estos centros. El texto del decreto entra en seria contradicción con las disposiciones del aludido decreto de I933 que contemplaba en el director de los Colegios Nacionales de Sordomudos y de Ciegos la inspección de las enseñanzas y centros $\left(\right.$ art. $\left.\mathrm{I}^{\circ}\right)$. Además, el Patronato Central incluye en su ámbito las escuelas de maternales pero no las de anormales.

Este Patronato no tiene incidencia práctica, el ministro Yébenes es sustituido en marzo de I 934 por Salvador de Madariaga que lo deroga y crea otro por Decreto de 3 de abril de ese mismo año, el Patronato Nacional de Cultura de los Deficientes $^{21}$. Esta institución se plantea bajo una consideración de organización flexible, sencilla y eficaz y tiene las funciones en el sentido cultural que la cuestión exija, se viene a decir en la exposición del decreto. Nominalmente las funciones del Patronato parecen ser las mismas que las de sus antecesores si bien expuestas en términos laxos: “(...), deben quedar afectos al Patronato todas las instituciones que se ocupen de las cuestiones culturales de los deficientes, así como la inspección de las de orden privado...".

Su terminología es atractiva y humanística y plantea ideas de interés como es la creación de un centro de recursos -como se llamaría hoy- para la educación especial con fonoteca y material en braille.

El ministro Madariaga cesa el 28 de abril de I934 y le sucede en el Ministerio de Instrucción Pública Filiberto Villalobos que no modifica ni sustituye el Patronato Nacional de Cultura de los Deficientes que hereda. Por otra parte no tenemos constancia de su incidencia en las enseñanzas de sordomudos, ni que participe en la política educativa sobre estas enseñanzas, y no porque la situación de las enseñanzas de sordomudos no lo requiriera, todavía el Colegio Nacional de Sordomudos seguía sin encontrar ubicación y por tanto clausurado y los grandes problemas de estas enseñanzas se mantienen. Los años I935 y 36 son un cúmulo de acontecimientos en estas enseñanzas: se

2I. Decreto de 3 de abril de I934 por el que se crea el Patronato Nacional de Cultura de los Deficientes. abre el Colegio Nacional de Sordomudos en condiciones muy precarias y separado definitivamente del de Ciegos, se crea una inspección del Estado e incluso se diseña una red de centros, pero todo se diluye en la situación política existente y luego la guerra civil.

\subsection{Conclusiones del periodo}

Procede, antes de planear las conclusiones del periodo I9IO-I936, hacer dos consideraciones, la primera es que con carácter general el conocimiento de partidos políticos, gobierno y Congreso de los Diputados sobre las enseñanzas de sordomudos (lo mismo ocurre con las de ciegos y anormales), no va más allá de la simpatía hacia estos colectivos y de la aprobación de los créditos para gastos del Colegio de Sordomudos y de Ciegos de Madrid establecidos en el Presupuesto del Estado, además de los principios generales de intervención en la educación o de la libertad de enseñanza que liberales y conservadores, respectivamente, defendían. Aunque, hay que decir que gracias al principio de intervención de los gobiernos en la educación defendido principalmente por liberales y también, de forma discontinua por conservadores, fue posible poner en pie tanto la reforma de las enseñanzas de sordomudos de principio de siglo XX como la creación de la educación especial y sus instituciones durante el primer tercio de éste.

La segunda consideración es que la actividad de los patronatos de sordomudos, ciegos y anormales, especialmente los de la Restauración y en menor medida en el periodo de la Dictadura y en menor todavía durante la República, está determinada por los grupos profesionales adscritos a la nueva etapa de la Educación Especial, es decir, por médicos, psicólogos y maestros, y un grupo heterogéneo de publicistas, juristas o defensores de estos colectivos. Muchos ministros de Instrucción Pública, que como tal son los responsables de la política educativa de las enseñanzas de educación especial, adaptarán su actividad a la influencia corporativa de aquellos para su pervivencia y justificación, porque además de la falta de unas ideas precisas 
y novedosas según se constata en el análisis de las funciones de la mayoría de los patronatos, la media de tiempo de los 39 ministros, algunos repiten cargo, entre I9IO-I936 es inferior a los 8 meses.

La conclusión es que ni la creación de estas instituciones ni su actividad se desenvolvieron de manera adecuada: un presupuesto bajo y mal distribuido, unas instituciones que se reconstituyen hasta en 8 o 9 ocasiones sin razones pertinentes como se ha expuesto más arriba y se plasma de forma comprensiva en un gráfico final, unas funciones o atribuciones de naturaleza diversa y muy amplias; muchas veces erráticas y cambiantes y un magma semántico confuso en cuanto a las denominaciones, hacen que su incidencia en las enseñanzas de sordomudos no tuvieran el rendimiento ni la consolidación institucional que hubiera sido deseable. Es cierto que los cambios de regímenes, las crisis sociales y económicas (I9I7 o I929), dos golpes de estado y una guerra civil, dificultan cualquier asentamiento.

3. Segunda etapa: los patronatos en el régimen de Franco (1939-1975)

Las políticas educativas de la administración franquista sobre estas enseñanzas así como sus patronatos tienen directa relación en su ejecución con un régimen que evoluciona desde la no intervención a la intervención declarada en las enseñanzas de educación especial (sordomudos, ciegos y anormales), y desde un régimen totalitario a otro tecnocrático con un fuerte control ideológico y político.

\subsection{Las políticas educativas de las enseñanzas de sordomudos}

El régimen en sus inicios toma dos decisiones de política educativa sobre las enseñanzas de sordomudos: no abrir el Colegio Nacional de Sordomudos cerrado por la Republica al inicio de la guerra, en tanto que dice no tener los recursos necesarios y mantener una política de no intervención en dichas enseñanzas. El Colegio se abre en 1947, posiblemente en atención a que la Ley de Instrucción Primaria de I945 establece la existencia de centros de sordomudos y el de Madrid es el único financiado por la Administración Central del Estado.

En los años 50 y principio de los 6o, la administración educativa tiene una intervención muy tímida en estas enseñanzas que se concreta en el aumento de las unidades del Colegio de Sordomudos de Madrid, la creación de unidades o secciones en el conjunto del país, la promoción de la construcción de centros de sordomudos con financiación social, fondos de diputaciones y ayuntamientos o el otorgamiento de interés social a los centros privados. También en I95I inicia la formación del profesorado especialista en sordomudos con un curso de 3 meses.

El régimen empieza a ser consciente de que su discurso de la participación de la sociedad, de los padres afectados y de la beneficencia en la tarea de la educación especial, es insuficiente para dar respuesta a la necesidades escolares de un régimen que se titula social y cristiano e inicia la programación de su presencia y la participación de la administración en estas enseñanzas. Uno de los medios elegidos para este fin es a través de un patronato. En I953 el gobierno justifica la creación del Patronato Nacional de Educación de la Infancia Anormal, en tanto que:

\footnotetext{
"(...) todavía no se ha abordado con ímpetu y eficacia el problema total de la educación y de la rehabilitación moral y social de un sector importante de la infancia y juventud españolas que acusan deficiencias o taras que es necesario contrarrestar mediante tratamientos de carácter especial” ${ }^{22}$ (preámbulo del decreto).
}

22. Decreto de 6 de marzo de 1953 por el que se crea el Patronato Nacional de Educación de la Infancia Anormal. 
El nuevo Patronato concibe "la necesidad de atender a la educación de la infancia anormal...", desde una "solución cristiana a este problema" y bajo el peligro de orden social que entraña no hacerlo. Y para estos efectos tendrá la colaboración de los servicios correspondientes de los Ministerios de Gobernación y Justicia. La presidencia de este Patronato corresponde al ministro de Educación Nacional RuizGiménez. Sus competencias en general son las tradicionales de los patronatos pero sin contemplar las consultivas ni las de intervención directa en el sistema escolar.

En I955, las autoridades estiman que dicha organización se debe perfeccionar y ampliar para cumplir la Ley de Educación Primaria de I945, creándose una "nueva institución de título más comprensivo y discreto": el Patronato Nacional de Educación Especial ${ }^{23}$. Bajo esta nueva fórmula el gobierno plantea nominalmente que "Es misión del Estado, (...) la noble tarea de la educación, que rige desde un plano superior, la fomenta en la esfera privada y la suple y completa por los órganos de gobierno".

Este Patronato mantiene la dependencia del Ministerio de Educación Nacional y sus atribuciones son consecuentes con las del Patronato de I953: una actividad centrada en la propuesta, ya de centros escolares o de creación de consultorios para el diagnóstico precoz y en los tradicionales de la organización de la formación del personal especializado, la tutela o la propaganda. Para una mayor eficacia de las actividades del Patronato, en provincias las secciones de Educación Especial de los Consejos Provinciales de Educación Nacional, son constituidos como organismos delegados del Patronato. El Gobierno le asigna al Patronato Nacional de Educación Especial la elaboración de un Plan Nacional de Educación Especial que incluye la formación profesional y la adaptación social, de forma específica para el tema de sordomudos, semi-sordos y disártricos, susceptible de tener una gran incidencia en estos colectivos.

23. Decreto de 9 de diciembre de 1955 por el que se crea el Patronato Nacional de Educación Especial.
Aunque con modificaciones en su estructura a lo largo de sus 20 años, la realización de sus funciones presenta un conjunto de incidencias en las enseñanzas de sordomudos, ciegos y anormales, de las que destacamos las que creemos más significativas:

- $\quad$ En I956 se institucionaliza y generaliza la presencia en la Comisión Permanente del Patronato de los directores de las Escuelas de Anormales, María Soriano y de Sordomudos, Miguel Baena y del presidente de la Federación Nacional de Sociedades de Sordos Españolas (FNSSE) Marroquín.

- Polaino-Lorente ( 1983 ) hace referencia a un estudio epidemiológico de los deficientes mentales en España llevado a cabo por el Patronato.

- Otros autores citan “un plan del Patronato Nacional de Educación Especial para dejar en Io años debidamente atendidas esta especialidad de la enseñanza (sordomudos)" ${ }^{24}$, hecho que anticipamos no se llegó a cumplir.

En I964, el gobierno dispone que una Comisión Central dependiente del Patronato redacte una nueva ordenación de especialidades, formación y titulación de todo el personal afecto a la educación especial. Además, esa Comisión interviene en los preparativos técnicos de la ordenación del sector de 1965 , que se realiza por medio del Decreto 2925/I965 regulador de la Educación Especial, en el que se le confiere nuevos cometidos al Patronato, incluido el volver a elaborar un Plan Nacional de Educación Especial.

En la segunda parte de los 6o, el Patronato contempla como el todavía Ministerio de Educación Nacional empieza a entender como propia la definición de una serie de políticas que se traducen en la construcción y financiación de los colegios o la formación del profesorado especial, si bien dejando amplios márgenes de libertad a la iniciativa privada y a la Iglesia

24. Entrevista al profesor del Colegio Nacional de Sordomudos, Rico. Diario $A B C$ de 20 de enero de 1958. 
Católica, siempre bajo un profundo control ideológico y político.

A finales de la década, el Ministerio de Educación y Ciencia está preparado para afrontar el mayor cambio metodológico y de ordenación del sistema educativo. El Libro Blanco sobre la reforma de 1969 como la Ley de Educación de I970 plantea un conjunto de consideraciones sobre la educación especial relativas a principios de organización, de red escolar o de escolarización con un tono de coherencia apreciable (capítulo XIII, parte $2^{\mathrm{a}}$ de Bases).

El régimen, al iniciarse la década de los 70, centra la realización de su política con las enseñanzas de sordos en el Instituto Nacional de Pedagogía de Sordos, heredero del Colegio Nacional de Sordomudos, tanto por sus medios humanos considerables y profesorado especializado, autonomía funcional del centro en cuanto a organización y dirección e instalaciones modernas y amplias que incluye una residencia y permiten la escolarización de un gran número de alumnos sordos. La formación del profesorado de sordos sigue siendo una de las competencias básicas del Instituto, el cual constituye el mejor motor de la política del régimen.

\subsection{Conclusiones}

El régimen de Franco se vale de la figura de los patronatos para justificar su intervención en la ordenación, dirección y gestión de la educación especial, y por ende, en las enseñanzas de sordos. A partir de los años 60 estas enseñanzas se conciben con un cierto grado de unidad con la de anormales y ciegos, en aspectos tales como la formación de los maestros especialistas y titulaciones de éstos. El planteamiento de la Ley General de Educación de I970 sobre la educación especial y la puesta en funcionamiento del Instituto Nacional de Psicopedagogía de Sordos de Madrid son los dos hitos que el régimen marca como fundamentales en las enseñanzas de sordos. La evaluación del grado de incidencia de las políticas educativas en las enseñanzas de sordos, ciegos y anormales se pospone a unas líneas siguientes.

\section{Tercera etapa: el posfranquismo y la Transición hasta 1978}

La última etapa de este estudio está destinada a hacer un análisis introductorio de las principales actividades del Real Patronato de Educación Especial y su incidencia en las políticas educativas del posfranquismo y de los primeros gobiernos de la Transición política de 1975 a I978, relativas a las enseñanzas de sordos. El año 78 es el de la proclamación de la Constitución Española y a los efectos de este estudio, el año de la desaparición del último Patronato no constitucional contemporáneo.

Un órgano creado en 1975 siendo ministro de Educación Martínez Esteruelas ${ }^{25}$ se constituye en elemento central de las políticas educativas de los años I975-I978, el Instituto Nacional de Educación Especial (en adelante INEE). En I976 se completa el aparato administrativo de la educación especial con un nuevo patronato, el Real Patronato de la Educación Especial ${ }^{26}$, presidido por la Reina de España y con las funciones genéricas de impulsar la educación especial regulada por el artículo 49 de la Ley General de Educación de 1970 y que sucede al casi homónimo Patronato creado en 1955.

Este tándem es refrendado por los gobiernos de la Transición política y supone un modelo institucional diferenciado del resto de la gestión que el Ministerio de Educación y Ciencia lleva a cabo con las otras etapas del sistema educativo. La administración educativa de esos años mantiene el sesgo segregador en la gestión de la educación especial que las distintas administraciones han mantenido históricamente.

El Real Patronato de Educación Especial (I97678 ) inicia planes generales como son el Plan Nacional de Prevención de la Subnormalidad y el Plan Nacional de Educación Especial. Sobre el primero, su análisis se puede realizar a través

25. Decreto II 5I/I975, de 23 de mayo, por el que se crea el Instituto Nacional de Educación Especial. 26. Real Decreto I023/I976, de 9 de abril, por el que se crea el Real Patronato de Educación Especial. 
de la Memoria del Real Patronato, I976-200I (Real Patronato, 200I:I4) y en cuanto al Plan Nacional de Educación Especial se diseña por el Real Patronato y su ejecución es responsabilidad del INEE conforme a las disposiciones vigentes, $\mathrm{y}$ sobre el cual hacemos algunas consideraciones:

"El Plan Nacional de Educación Especial nace con el firme y decidido propósito de hacer frente, de forma global y coherente, a los graves problemas que la educación de los niños deficientes e inadaptados presentan en nuestro país, problemas que hay que referir no solo a la notoria falta de recursos, sino también a la ausencia de criterios orientadores y definitorios" (Real Patronato de Educación Especial, I978:33).

Hay que tener en cuenta para un análisis adecuado que "El Plan es un plan-marco, plan básico o previo", "no es inmediatamente operativo" (Real Patronato de Educación Especial, I978: I 5-I6).

Bajo estas ideas y términos, el Plan supone uno de los mejores análisis de aquellos años en cuanto a la situación de la educación especial y constituye una valoración crítica hecha tanto por los profesionales del sector como por responsables del mismo sistema educativo representado por el Real Patronato de la Educación Especial y por el INEE. De sus conclusiones se puede inferir que las políticas educativas del régimen de Franco en las enseñanzas de sordos, ciegos y anormales han sido muy limitadas en cuanto a sus resultados y que la Ley General de Educación de 1970 en lo que a la Educación Especial se refiere está implantándose muy lentamente, cuando no insuficientemente.

El mismo INEE considera “dramática y escandalosa” la situación de la Educación Especial ya que hasta el momento "solo menos de un cuarto de la población estimada" la recibe, además define "de escasa calidad a los cursos de formación del profesorado y en general menciona como irritante el estado de abandono del sector" (Real Patronato de Educación Especial, I978:33).
Según las estimaciones del Plan, la población con deficiencias de o a I 8 años alcanza los 330000 individuos y solo están escolarizados el 21,5\%, es decir 72000 (Plan Nacional de Educación Especial, I978: 67-67 y I 59 a I79). Se cifran en casi cuarenta mil quinientos millones de pesetas la inversión a ejecutar en los presupuestos de los 4 próximos años, solo para dar respuesta educativa.

El Plan se basa y fundamenta en una serie de principios aplicados en otros países en el trato a las personas objeto de educación especial, entre otros, los procedentes de la experiencia angloamericana, el informe Warnock y las realizaciones nórdicas, fundamentalmente, también se consideraron, pero a cierta distancia determinados planteamientos de la Ley de Educación de I970, y todas estas ideas y principios se hacen presentes en el Plan con relación a la normalización de los servicios, integración escolar, sectorización e individualización de la enseñanza. El Plan contribuye a fijar estos principios en nuestro ordenamiento jurídico: Constitución de I978, Ley de Integración Social de los Minusválidos de 1982 (LISMI) o en las regulaciones de la educación especial de I982, I985 y posteriores.

Cabe citar en el orden de las ideas y realizaciones el apoyo prestado por el Real Patronato a la Comisión Especial del Congreso de los Diputados para el estudio de los problemas de los disminuidos físicos y psíquicos, presidida por el diputado Trias Fargas en 1977 ${ }^{27}$, la cual presenta un Proyecto de Ley para la atención de los Disminuidos Físicos, Mentales y Sensoriales, articulado en 4 títulos y un Plan Financiero para la Educación Especial desde I979 a I983, y que en I982 da lugar a la referida LISMI.

La acción del Real Patronato de Educación Especial y el Instituto Nacional de Educación Especial tiene incidencia sobre las enseñanzas

27. La colaboración entre el Real Patronato de Educación Especial y la Comisión Especial de Trias Fargas se concretan en unos borradores de ley tanto de ámbito general como uno específico relativo a la Educación. Archivo del Congreso de los Diputados, Legajo I 358 Único 
específicas de sordos que a finales de la década de los 70 cuenta con un total de unos 4700 alumnos sordos e hipoacúsicos matriculados en centros especiales o unidades de la misma naturaleza (Ministerio de Educación y Ciencia,I981:84), distribuidos en una red pública y privada que alcanza los 40 centros, si bien de éstos, I 3 o I 4 solo sobrepasan los Ioo alumnos.

La intervención combinada de estas dos instituciones se puede concretar en la creación y autorización de al menos 7 centros específicos de sordos, en el periodo I 975 -80 y en cuanto al sistema de formación del profesorado de audición y lenguaje, ambos organismos junto a los nuevos Institutos de Ciencias de la Educación y el Instituto Nacional de Pedagogía de Sordos participan en dos convocatorias.

Como conclusión de este periodo se puede decir que el Real Patronato de Educación Especial es el último patronato contemporáneo no constitucional o previo a los valores constitucionales de 1978 pero que contribuye a su definición especialmente en su última etapa, también es el último patronato en depender del Ministerio de Educación. Entre septiembre y diciembre de I978 se transforma en el Real Patronato de Educación y Atención a Deficientes, después en el de Prevención y Atención a Personas con Minusvalía y por último en el Real Patronato sobre Discapacidad, que es el único en nuestra historia creado por una ley; aunque sea de medidas fiscales (Ley I $4 / 2000$, de 29 de diciembre) y en consecuencia objeto de debate parlamentario.

\section{Conclusiones generales}

Con la intención de completar las conclusiones presentadas en las etapas históricas se plantean otras más genéricas de evidente interés:

- Primera. Las políticas educativas de los gobiernos del siglo XX en España, hasta la década de los años 80 , situaron la gestión y dirección de las enseñanzas de sordomudos o sordos en órganos externos, creados ex profeso con competencias especializadas y comprensivas de la totalidad de las necesidades de estas personas y en cuya estructura se admitía la presencia de profesionales de los sectores implicados y de la sociedad, bajo el control del ministerio correspondiente de Instrucción pública o de Educación y finalmente de ministerios de otras naturalezas.

- $\quad$ Segunda. La incidencia de los patronatos en la educación de las personas sordas se puede fijar en dos dimensiones significativas: A) La administración educativa, tanto en el periodo estudiado de los patronatos como en épocas anteriores (siglo XIX) siempre fue receptiva a su modo y compasiva con los sordomudos y su causa educativa, lo que llevó durante todo el siglo XIX y una buena parte del XX a confundir por la propia administración la acción benéfica o caritativa con la educadora. B) La administración educativa central, tanto en el periodo de los patronatos como en el siglo XIX, en el desarrollo de las políticas educativas siempre fue especialmente interventora en la imposición y definición de métodos y enfoques educativos para la enseñanza del sordomudo, siendo mayormente en el tiempo el de naturaleza oralista, instrumentándose por medio de políticas de formación del profesorado, selección del personal (oposiciones y contrataciones) y una política curricular que establecía los objetivos de oralización e integración del sordomudo en la sociedad.

- $\quad$ No será hasta los primeros años $90 \mathrm{del}$ siglo XX, y representado en el Real Decreto 696/I995, de ordenación de la educación de los alumnos con necesidades educativas especiales. BOE de I 3 de mayo de I995, cuando las políticas del gobierno provoquen un cambio en el marco conceptual de las enseñanzas de sordos al contemplarse la posibilidad de incorporar la lengua de signos en los centros educativos, abriéndose 
el camino para una oferta educativa que contase en los currículos con este código y con profesionales sordos e intérpretes de lenguas de signos. Esta vía será paralela al tradicional y mayoritario modelo de oralización del alumnado sordo.
Se aporta mediante un cuadro una información gráfica que facilite la comprensión de la evolución o transformación de los distintos patronatos (I9IO-I978).

\section{Cuadro 1. Evolución o transformación de los distintos patronatos (1910-1978)}

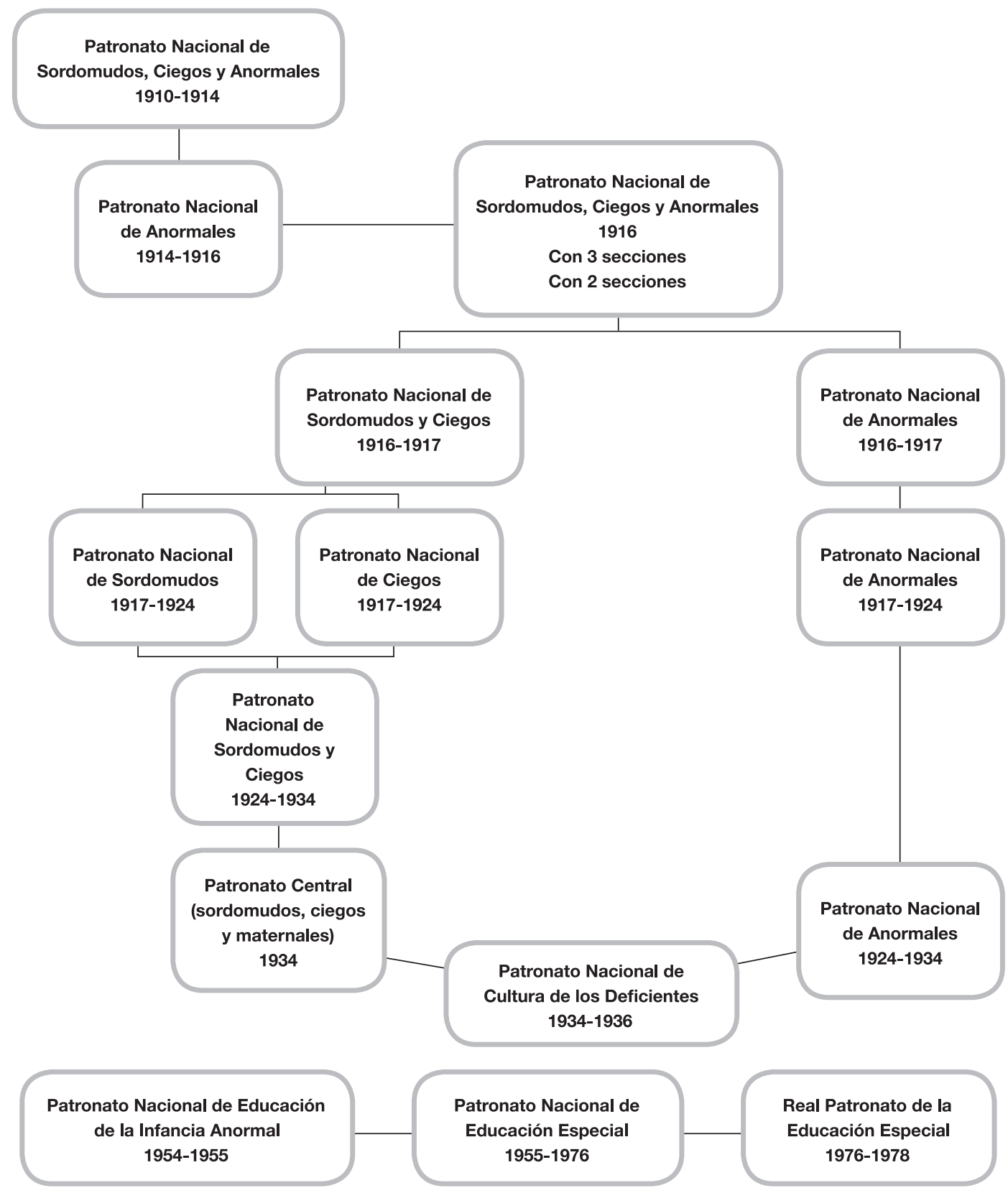


Referencias bibliográficas

Artola, M. (I975): Partidos y Programas politicos I808-I936, Madrid: Aguilar.

Canales, A. F. (20I3): "La modernización del sistema educativo español, I 898-1936". Revista de Pedagogía Bordón, 65 (4), I I I-I I 2.

Carr, R. (2000): España I 808-1975, Barcelona: Ariel Historia.

Committee of Inquiry into education of handicapped children and young. Warnock report (1978): Special Educational Needs. People, London: HMSO. Great Britain. Parliament. House of Commons.

Del Pozo, A. ( I980): "La educación de deficientes mentales en España: Los cincuenta primeros años de su desarrollo (I875-I925)”. Revista Española de Pedagogía, I48.

España. Real Decreto de 22 de enero de I9 Io estableciendo en este Ministerio un Patronato Nacional de sordomudo, ciegos y anormales. Gaceta de 24 de enero de I9ro. Colección Legislativa de España, Tomo XXXVII. Volumen $I^{\circ}$, Madrid: Imprenta de la Revista de Legislación.

España. Real Orden de 20 de abril de I9ro por la que se declara constituido provisionalmente el Patronato Nacional de Sordomudos, Ciegos y Anormales. Gaceta de 20 de abril de I9ro.

España. Real Orden de 2 I de julio de I9 Io por la que se establece la constitución definitiva del Patronato Nacional de Sordomudos, Ciegos y Anormales y su división en tres secciones. Gaceta de 22 de julio de I9ıо.

España. Real Decreto de 24 de abril de I9I4, reformando el Patronato Nacional de Sordomudos, Ciegos y Anormales, disponiendo que en lo sucesivo se denomine Patronato Nacional de Anormales, y que su objeto, composición, atribuciones y funcionamiento se rijan por las disposiciones que se publican. Colección Legislativa de España, Tomo CLE Volumen I de I9I4, Madrid: Imprenta de la Revista de Legislación.
España. Real Orden de 2 de marzo de I9I 5 por la que se aprueba el Reglamento del Patronato Nacional de Anormales. Gaceta de Madrid, núm. 72, de I3/O3/I9I5, pp. 774 a 775 .

España. Real Decreto de ro de marzo de I916 restableciendo la organización del Patronato de Sordomudos, Ciegos y Anormales, creada por el de 22 de enero de I9Io. Gaceta de I 5 de marzo de r9i6. Colección Legislativa de España, Tomo LVI Volumen I de I9I6, Madrid: Imprenta de la Revista de Legislación.

España. Real Decreto de 8 de agosto de I9I6 disponiendo que el Patronato del Instituto Nacional de Anormales y especial de Sordomudos y de Ciegos, se divida en dos secciones: una de Sordomudos y Ciegos y otra de Anormales. Gaceta de 9 de agosto de I9I6. Colección Legislativa de España, Tomo LVII Volumen $2^{\circ}$ de I9I6, Madrid: Imprenta de la Revista de Legislación.

España. Real Decreto de 22 de diciembre de I9I6 por el que se establece que las dos secciones del Patronato se constituyan en dos patronatos independientes. Gaceta de Madrid, núm. 358 , de 23 de diciembre de I9I6, página 703 .

España. Real Decreto de 24 de agosto de I9I7 reorganizando en tres Patronatos Nacionales, que se denominaran, respectivamente, de Sordomudos, de Ciegos y de Anormales mentales. Gaceta de 26 de agosto de I9I7. Colección Legislativa de España, Tomo LIX Volumen $2^{\circ}$ de I9 17, Madrid: Imprenta Hijo de Reus.

España. Real Decreto de I 3 de septiembre de I924 declarando disueltos los Patronatos Nacionales de Sordomudos, de Ciegos y de Anormales y creándose los Patronatos Nacionales de Sordomudos y de Ciegos y de Anormales. Gaceta de I4 de septiembre de I924. Colección Legislativa de Instrucción Pública, Madrid: Imprenta "La Enseñanza".

España. Decreto de I 6 de febrero de I934, por el que se crea el Patronato Central, Gaceta de 
I 8 de febrero de 1934. Biblioteca Nacional, Hemeroteca. Microfilmado.

España. Decreto de 3 de abril de 1934 por el que se crea el Patronato Nacional de Cultura de los Deficientes. Gaceta de 6 de abril de I934. Biblioteca Nacional, Hemeroteca. Microfilmado.

España. Decreto de 6 de marzo de 1953 por el que se crea el Patronato Nacional de Educación de la Infancia Anormal. Boletín Oficial del Estado, 2I de marzo de I953, núm. 80, pp. I486 a I 487 .

España. Decreto de 9 de diciembre de 1955 por el que se reorganiza el Patronato Nacional de la Infancia Anormal, que se denominará "Patronato Nacional de Educación Especial" y se crean sus Secciones provinciales. Boletín Oficial del Estado, 2 de enero de 1956, núm. 2, pp. 28 a 30.

España. Ley I4/ı970, de 4 de agosto, General de Educación y Financiamiento de la Reforma Educativa, Boletín Oficial del Estado, 6 de agosto de I970, núm. I87, pp. I2525 a I 2546

España. Decreto I I 5 I/I975, de 23 de mayo, por el que se crea el Instituto Nacional de Educación Especial. Boletín Oficial del Estado, 3 de junio de I975, núm. I32, pp. II769 a II77I.

España. Real Decreto I023/1976, de 9 de abril, por el que se crea el Real Patronato de Educación Especial y se modifican determinados artículos del Decreto I I 5 I/I975 de 23 de mayo. Boletín Oficial del Estado, ro de mayo de I976, núm. II2, pp. 9016 a 9017.

España. Real Decreto 2828/I978, de I de diciembre, por el que se regula el Real Patronato de Educación y Atención a Deficientes. Boletín Oficial del Estado, 7 de diciembre de I978, núm. 292, pp. 27684 a 27685 .

España. Ley I3/I982, de 7 de abril, de integración social de los minusválidos, Boletín Oficial del Estado, 30 de abril de I982, núm. I03, pp. IIIO6 a IIII2.

González, S. (I9I7): “El Sr. Borrell y los niños anormales”. Revista España de 25 de enero de I9I7. Seudónimo del Dr. Lafora.
González, S. (I9I7): “Los escándalos de la enseñanza”. Revista España de 26 de abril de I9I7.

Granell, M. (1934): Historia de la Enseñanza del Colegio Nacional de Sordomudos, Madrid: Imprenta del Colegio Nacional de Sordomudos.

Lane, H. (1989): When the Mind Hears. A history of the deaf, New York: Random House

Ministerio de Educación y Ciencia (I969): La Educación en España. Bases para una política educativa, Madrid: MEC.

Ministerio de Educación y Ciencia (I98I): Estadística de la Educación Especial. Análisis cursos I979-80 y I980-8I, Madrid: MEC, Gabinete de Estadística.

Ministerio de Hacienda (I9I3, I9I7,I920 y I922): Presupuestos Generales del Estado para los años económico de I9I3, I9I7, I920-2I y I922-23, Madrid: Imprenta de Sucesores de M. Minuesa.

Ministerio de Instrucción Pública y Bellas Artes (1908): Primera Asamblea Nacional para el mejoramiento de la suerte de los sordomudos $y$ de los ciegos. Comunicaciones. Actas. Exposición aneja, Madrid: Imprenta del Colegio Nacional de Sordomudos y de Ciegos.

Ministerio de Instrucción Pública y Bellas Artes (1908): Estadística escolar de España en I908. Publicada por la Subsecretaria del Ministerio, Madrid: Imprenta de la Dirección General del Instituto Geográfico y Estadístico.

Molina, P. (I900): Instituciones Españolas de sordomudos y de ciegos. Consideraciones sobre lo que son y deberían ser estos centros, Madrid: Imprenta de Hernando.

Molina, P. (I903): Discurso leído el I 8 de octubre de 1903 en la solemnidad de premios a los alumnos de aquel establecimiento por el profesor D. Pedro Molina Martín, Madrid: Imprenta del Colegio Nacional de SordoMudos y de Ciegos.

Molina, S. y Gómez, A. (I992): Mitos e ideologías en la escolarización del niño deficiente mental. Cuándo y cómo surgieron en España las escuelas de educación especial, Zaragoza: Mira Editores. 
Navarro Morgati, M. L. (I9I7): "El Instituto Nacional de Sordomudos. Notas para su reorganización”. Boletín Escolar: $\mathrm{n}^{\mathrm{i}} \mathrm{\textrm {i }}$, pp. 287 y 288 . $\mathrm{N}^{\mathrm{o}}$ I 5 , pp. 3 I 2 y 3 I $3 . \mathrm{N}^{\circ}$ I6, pp. 337 y 338 y No I7, pp. 369 y 370 . Tomo I. Editorial Calleja.

Navarro Morgati, M. L. (I926: "Los métodos para la enseñanza del lenguaje de los sordomudos". Revista de Pedagogía, Año V, I926, 486-496.

Orellana, J. (I9I7): La enseñanza de la palabra a los sordomudos, Madrid: Librería de los sucesores de Hernando.

Pereira, F. (1904): “Necesidad y medios de establecer en España escuelas para anormales". La Escuela Moderna, no I6I, 479-506.

Polaino-Lorente, A. (I983): "Las cuatro últimas décadas de Educación Especial en España”. Revista Española de Pedagogía, n ${ }^{\circ}$ I60.
Puelles, M. (1986): Educación e ideología en España, Barcelona: Labor.

Real Patronato de Educación Especial (I978): Plan Nacional de Educación Especial, Madrid: Edición del Patronato.

Secretaria Ejecutiva del Real Patronato (200I): Memoria del Real Patronato (I976-200I), Madrid: Edición del Real Patronato sobre Discapacidad.

Urquijo, J. M. (2008): Gobiernos y ministros españoles en la edad contemporánea, Madrid: CSIC.

Yuste de Santos, J. (2003): Juan Luis Marroquín, la fuerza de la unidad, Madrid: Fundación CNSE. 